cycle. The role of vitamins $\mathrm{K}$ and $\mathrm{E}$ in oxidative phosphorylation is still a matter of some uncertainty and speculation, and cannot yet be discussed in terms of known enzymes. The chapter on ascorbic acid does in fact contain a good deal of enzymology, but treats the metabolism of the compound rather than its coenzyme function, which is not known.

Volume 4 of the present series is the first of three in which the main groups of enzymes and a number of individual enzymes will be surveyed. It deals with enzymes hydrolysing peptide, glycosidic and ester bonds. The chapters are arranged in groups, in each of which the first chapter is a survey of the field covered by those following. In the volume under discussion the 'survey" chapters are: "Peptide Bond Cleavage", by Emil Smith; "Other C-N Bond Hydrolyses", by J. E. Varner; "Cleavage of $O$ - and $S$-glycosidie Bonds", by E. H. Fischer and E. A. Stein, and "Carboxyl Ester Cleavage", by D. K. Myers. This arrangement helps greatly to unify what might otherwise be merely a series of disconnected monographs. There is some evidence, too, of editorial efforts to avoid overlap between the chapters.

The general stendard of this volume is very high, although inevitably the time taken to assemble manuscripts and produce such a volume has meant that in some cases recent developments are not included and the articles are somewhat out of date. Most of them, however, will probably remain authoritative sources for some time to come. It is not possible here to mention many of the 33 chapters; however, some stand out as giving a stimulating account of an enzyme, in which a large body of factual information is critically assembled, and used as the basis for a discussion of the mechanism of the enzymatic catalysis or the metabolic importance of the enzyme. Such chapters are useful reading for all enzymologists, whether or not their own work is connected with the enzymes under discussion. They include those on chymotrypsin and trypsin by $\mathbf{P}$. Desnuelle; papain by E. L. Smith and J. R. Kimmel; $\alpha$-amylases by $D$. French; $\beta$-galactosidases by $K$. Wallenfals and $O$. P. Malhotra; and acotylcholinesterase by $\mathrm{I}$. R. Wilson.

The Enzymes is well printed on pleasant paper, and the volumes are strongly bound and are not unpleasantly large to handle. The whole work is too large to be regarded as a text-book, but as a reference book it should be on the shelves of every biochemist whose activities demand a reasonable knowledge of enzymology.

EDwin C. WebB

\section{IDENTIFICATION, PROPERTIES AND USES OF INDIAN TIMBERS}

\section{Indian Woods}

Their Identification, Properties and Uses. By Dr. K. A. Chowdhury and S. S. Ghosh. With the assistance of K. Ramesh Rao and S. K. Purkayastha. Vol. 1: Dilleniaceae to Elaeocarpaceae. Pp. liii $304+30$ plates. (Delhi: Manager of Publications, 1958.) Rs. 25.50 n.p.; $39 s$.

7 HE publication of a new reference book on Indian timbers is a notable event, for Gamble's Manual of Indian Timbers (1922) is now out of date and the more recent Commercial Timbers of India (1932) by Pearson and Brown omits many of the timbers that are now being exploited commercially.
The volume under review is the first of a series of six. each dealing with the wood of 250-300 tree species that occur in the Indian sub-continent and are represented in the wood collection at the Forest Research Institute at Dehra Dun. The chief purpose of the book is to enable the timbers to be identified by characters that are to be seen with the naked eye or hand lens, and to assess the working qualities of the woods from their structural and physical properties. Brief notes on the habit and distribution of the species are given, together with some particulars of their strength, seasoning properties, durability, working qualities, supplies and uses. The descriptions of the woods are illustrated by photographs $(\times 10)$ of transverse sections. These illustrations, which are of excellent quality and well reproduced, add considerably to the value of the book. The scientific names and the trade and common names are given in separate indexes and there are appendixes dealing in tabular form with the nomenclature of species, classification of the woods by uses and by anatomical structure respectively.

After a valuable introduction of 53 pages, the main part of the book consists of descriptions of the woods under the botanical families to which they belong. For the sequence of families the authors have used the modified form of the Bentham and Hooker system adopted by Metcalfe and Chalk in Anatomy of the Dicotyledons. The volume now under review covers 20 families ranging from the Dilleniacese to the Elseocarpacene and includes the important timberyielding Dipterocarpaceae, more than 70 pages being devoted to this one family. At the end of each family there is an extensive bibliography.

The authors are at pains to dispel the popular con ception that India is the potential source of large supplies of many diverse timbers. They emphasize that the number of timbers available in large quan. tities is not more than sixty or so, the most important being teak (Tectona), sal (Shorea robusta) and deodar (Cedrus deodara). Before 1939 the number of timbers handled commercially was 300-350, but about 500 were in use during the Second World War. Now the local exploitation of relatively unknown woods is becoming more common owing to the increased demand for timber resulting from industrial expan sion and to the difficulties of transport.

In discussing the general question of how far wood structure can serve as an aid in taxonomy, the authors, in my opinion, take a somewhat pessimistic view. It is quite true, as the authors point out, that in many families the individual species, and sometimes the genera, are not easy to separate on the basis of wood structure. This, however, does not exclude the possibility of using wood characters for diagnostic purposes, and they are often valuable in determining the correct family relationships of genera the taxonomic position of which is uncertain from exo. morphic characters alone. The great danger in the study of systematic anatomy is to rely too exclu. sively on wood characters alone without taking the histology of the rest of the plant into consideration.

The authors are to be congratulated on having produced the first volume of a most valuable book which cannot fail to be welcomed by botanists, foresters and wood technologists, and the publication of further parts will be eagerly awaited. It is a matter for regret that the quality of the binding does not do justice to a reference book of such undoubted importance. 